\title{
Spatial Distribution, Pattern and Accessibility of Urban Population to Health Facilities in Southwestern Nigeria: The Case Study of llesa
}

\begin{abstract}
Adetunji, Musilimu Adeyinka (Ph D)
Department of Geography

Faculty of Arts and Social Sciences,

Federal University Lokoja, Kogi State, Nigeria

Doi:10.5901/mjss.2013.v4n2p425

Email: maadetunji@yahoo.com Phone No.+234-8066245425

Abstract

Health facilities are not evenly distributed to the people in Nigeria. Much research works on people accessibility to health facilities are concentrated in major urban centres in Nigeria. This paper examined the accessibility characteristics of urban population to health facilities in a medium sized city of llesa, Nigeria. Primary and secondary data were used for the research. A total of 600copies of questionnaire were randomly distributed to the head of households in 11 zones identified in the city. Secondary data were obtained from documentary sources. Descriptive and inferential statistics were used to analyze the data. The findings revealed that health facilities in llesa were unevenly distributed in the form. Health trips in llesa were therefore skewed towards Zones with more health services. The result of the analysis of variance further showed the existence of significant variations in accessibility to health facility among the sampled population in the study area. The paper concludes that some of the public health facilities in Ilesa should be upgraded to the status of General Hospitals given the growing nature of the town as the most important town in its region.
\end{abstract}

Keywords: Health, Urban, Income, Transport and planning Implication

\section{Background}

A large percentage of previous works on access to health facilities in Nigeria principally focused on first order centers like Lagos, Ibadan and Benin where Specialist hospitals and numerous private clinics have been in existence for many decades.(Adagbasa, 2008) Studies on trips to health facilities in second order or medium sized cities in Nigeria are very few. Incidentally, this category of centres constitutes bulk of Nigeria's state capitals and headquarters of Local Government Areas The paucity of this type of study is unwarranted if the health and social well being of Nigerians are to be properly understood and incorporated in to the planning programmes of the various tiers of government. (Adetunji, 2010).

Soon after political independence in the 60s, a major concern of most countries in Africa South of the Sahara was the provision of adequate health care health care systems to meet the needs of their people particularly where such services were grossly insufficient. Thus, studies have shown that adequate health care system has a direct positive correlation to the socio-economic and general well being of the people it serves.(Adesanya, 2002; Judy, 2005). Partly based on this development, every successive Nigerian governments in collaboration with other Non-governmental agencies devoted substantial part of their annual budgets to health care provision and delivery.(Olawuni, 2007). Despite this noticeable huge financial commitment to health sector, many citizens are still being denied easy access to good health care services mainly, as a result of the inability of the Government to respond as quickly as possible to increasing demands for health facilities to match the rate of urbanization. Many urban residents in developing cities subsequently have to travel over a long distances and spend a large proportion of their income in order to procure health services which are relatively provided elsewhere (Adetunji,2010; Adesanya el al, 2002; Judy et al, 2005). This study examines accessibility characteristics of residents of llesa of South Western Nigeria, to health facilities. The work is part of a larger study on Ilesa (Adetunji, 2010). If many of the problems bedeviling the delivery of adequate and qualitative health services in Nigeria's big cities and towns are to be solved. There is need for this type of study which can assist the politicians and policy formulators in initiating and promoting people's oriented programmes in their areas of jurisdiction. 


\section{Theoretical Frame Work and Literature Review}

There are a number of theories and concepts in geographic literature which attempt to explain the spatial distribution and patterns of geographic phenomena in space. The Central Place Theory, the p-Median Model and the Market Area Analysis are some of such theories. (Ayeni, 1979). The central place theory apart from recognizing the spatial distribution of settlements also, identified settlement hierarchy based among other things on the type's services that settlements provide (Christaller 1966, Ayeni 1979). Thus, higher order centres/services and lower order centres/goods will command differential market areas because they present different range of opportunities to their customers. In a review of literature on barriers to access to health services, Ensor and Cooper (2004) regard distance and time as two crucial factors affecting the procurement of health services in many low income countries. According to them, the direct costs of transport invariably account for a substantial percentage of overall expenditure in health care equation of individuals. For instance, in a study carried out in North-east brazil, travel cost of procuring health care have been estimated at $25 \%$ of total expenditure on health (Terra de Souza et al, 2000) and 28\% in Cameroon (Sauerborn et al, 1995). In Bangladesh, studies have shown that transport cost to health services centres is next to expenditure on drugs by patients (CIET Canada, 2002). Besides, cost of transport, the physical access to health services is also critical particularly where the locations of such facilities are not objectively located (Andrew, 1997).

Some other scholars have focused on the significant role of the socio-economic characteristics of urban residents on their access to health care services in both developed and developing countries,( Andrew, 1997: Olawuni, 2007). In a study of access to health care among urban minority communities, Andrew (1997) observed that health care providers are less accessible to the urban poor because of their financial predicament. According to him, many urban poor are often sick given the unhealthy environment they live in and because most of them seek for treatment only when critically ill, they seem to expend more on treatment.

In Nigeria, Adesanya et al (2002) have examined the mobility of urban poor to various services in Adamawa (Yobe State), Lagos (Lagos State), Port Harcourt (Rivers State), Onitsha (Anambra State), Jos (Plateau State) and Kaduna (Kaduna State). This nationwide study revealed that accessibility characteristics of urban poor to the various social and economic centres are generally very low. According to them, the urban poor travel over considerable distances to different activity centres in Nigeria. For instance, it was found that only $42 \%$ of the populations were located within one kilometre of such services as schools (primary and secondary), pipe borne water points, primary health centres and dispensaries. On the other hand, $25.1 \%$ of the population travels beyond nine kilometers in order to get to the nearest hospitals. Adesanya et al (2002) study also noted the influence of income of urban residents on their accessibility and frequency of trips to hospitals. They found that low income earners make fewer trips to hospitals because of high transport cost and treatment charges.

It is clear from the foregoing paragraphs that there is a dearth of works on the accessibility of the urban population to health facilities in the medium-sized cities and towns in southwestern Nigeria in particular and elsewhere in Africa in general. This neglect is unwarranted in a growing economy like Nigeria where individual good health and physical and mental well being should be regarded as an agent of national socio-economic development. This study is therefore designed to examine the accessibility characteristics of urban residents to health facilities in one of Nigeria's rapidly developing city of llesa in ljesa region in Osun state. The study hopes to add value to the expanding body of literature on urban health care delivery system in Nigeria.

\section{The Study Area}

llesa metropolis is the study area. llesa is the most important settlement in ljesa region of Southwestern Nigeria (Peel, 1983). Ilesa metropolis consists of two large local government areas of llesa West and llesa East. Both Council areas are bounded in the North, West and South by Obokun, Atakumosa and Oriade Local Government areas respectively. The study area is located 32 kilometers North-East of the ancient Yoruba town of lle-lfe and shares the same senatorial seat in the Upper National Legislative Chamber. Osogbo, the Osun State Capital is located 30 kilometers South-west of llesa. llesa's location is strategic as routes linking other Yoruba states pass through it.( See figure 1)

The population of llesa was 72,029 in 1952 when the first national census was carried out in Nigeria outside Lagos. This is increased to 165,822 in 1963 and 138.953 in 1991. At present the population of llesa is estimated at 210,141. (NPC, 2006) .

llesa is situated on an undulating plain with an average elevation of about 365 meters above the sea level and a relative relief of 15 meters. The town lies within the rainforest region of South-Western Nigeria. It enjoys an equatorial 
type of climate with wet and dry seasons. The former is between March and November of every year, while the dry season starts in November and terminates in March. December and January are coldest months in the year due to the influence of the dry North-East trade winds.

The soil of llesa region is of ferruginous tropical lateritic type derived from crystalline basement rocks. The town's well-drained clay soil supports the growth of a number of food and cash crops like palm trees, cocoa and yam. Thus, farming and trading in varieties of goods are the major occupations of ljesa people. As a result of their active involvement in trades across Nigeria, ljesas are nationally and internationally known (Peel, 1983). Cash crops like Cocoa, Palm produce, Kola nut are cultivated for export and long internal distant markets. (Ogundahunsi, 1995). Food crops like yam, rice, maize, cassava, tomatoes and vegetables are cultivated either for domestic consumption or urban daily or periodic markets. All this gives llesa its strong socio-economic base and a vibrant manufacturing component.

A wide variety of health services are provided by both public and private concerns in llesa. Such services range from simple health providers to specialist hospitals. The Wesley Guild Hospital which is a arm of Obafemi Awolowo University Teaching Hospital Complex at lle-lfe was established by the Methodist Church in 1926. It provides special hospital services in the area of Psychiatry, Gynaecology etc. The private and other public owned clinics, maternities and dispensaries provide general services for the populace.

Given the presence of some large industries (a large brewery and a steel manufacturing factory) and a number of tertiary institutions (a degree awarding College of Education, a Nursing School as well as a School of Health Technology), llesa may in future witness not only political transformation, but also drastic demographic and socioeconomic changes which would call for a more serious approach to the city's planning strategies including a provision of health infrastructure.

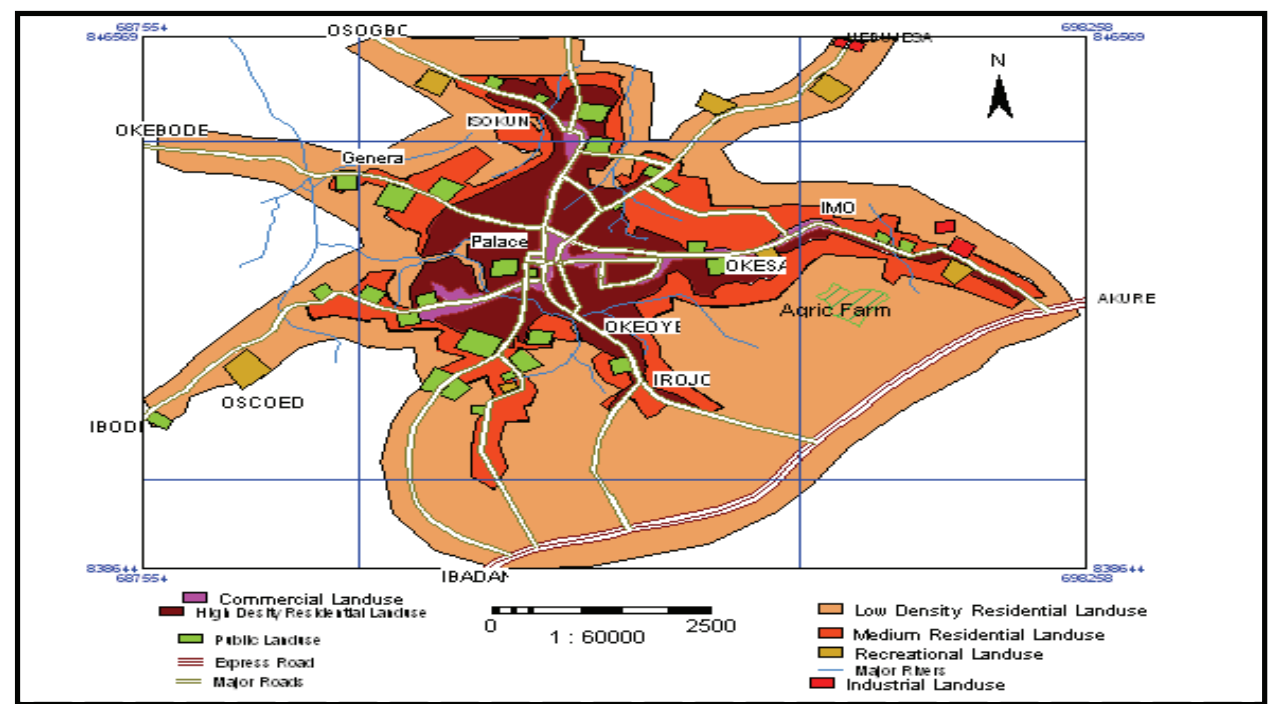

Figure 1: Map of the Study Area.

\section{Methodology}

Both primary and secondary sources of data were used for this study. The primary data were collected through the administration of well structured questionnaires, field observations and the use of Geodetic Positioning System (GPS). Multi-stage sampling procedure was used in the administration of the questionnaires. First, the study area was divided into eleven (11) zones originally designed for a larger study. (Adetunji, 2010). In each zone, all the buildings were counted and appropriately numbered in alphabetical order for the purpose of randomly selecting one every 20 buildings. A questionnaire was administered on head of one household in each of the selected buildings, given a total of six hundred questionnaires. The questionnaire was designed first and foremost to gather information on the socio-economic characteristics of the sampled households particularly with reference to their income, the type of health facility (facilities) 
they usually patronize whenever they are sick, the frequency of their visit to such health care providers, the distance travelled from their residence to the health facility and mode of transport commonly used to such centres.

Secondly, data were also obtained from relevant literature and archival sources in both llesa and lle-lfe where a number of in-depth researches on health facility have been conducted in recent years (Olawuni, 2007). Descriptive and inferential statistics were used to analyze the data. The descriptive statistics used includes tables of percentages, charts and graphs to depict the distribution patterns of health care providers in the city, the distance travelled to health facilities as well as the modal choice of patients across the eleven zones. The Analysis of Variance was employed to examine the travel patterns of patients to health care facilities while a Multiple regression analysis was used to examine the contribution of the distribution of health facility, transport attributes and socio-economic characteristics of urban population to health care providers in the study area. The Geodetic Positioning System (GPS) was used to capture the Geographic Coordinates of Public Health Care Providers in the city.

\section{Results and Discussion}

There are only two major hospitals in llesa, namely, the Federal owned Wesley Guild Hospital (which is an arm of the Obafemi Awolowo University Teaching Hospital, Ile-lfe) and the Osun State owned General Hospital. There are other sixteen (16) privately owned health centres or clinics whose services are generally regarded as expensive by majority of the respondents in llesa. There are also twenty two (22) primary health care centres and four dispensaries scattered in different locations in llesa. The patterns of distribution of these various health services are shown in table 1 below and figure 2

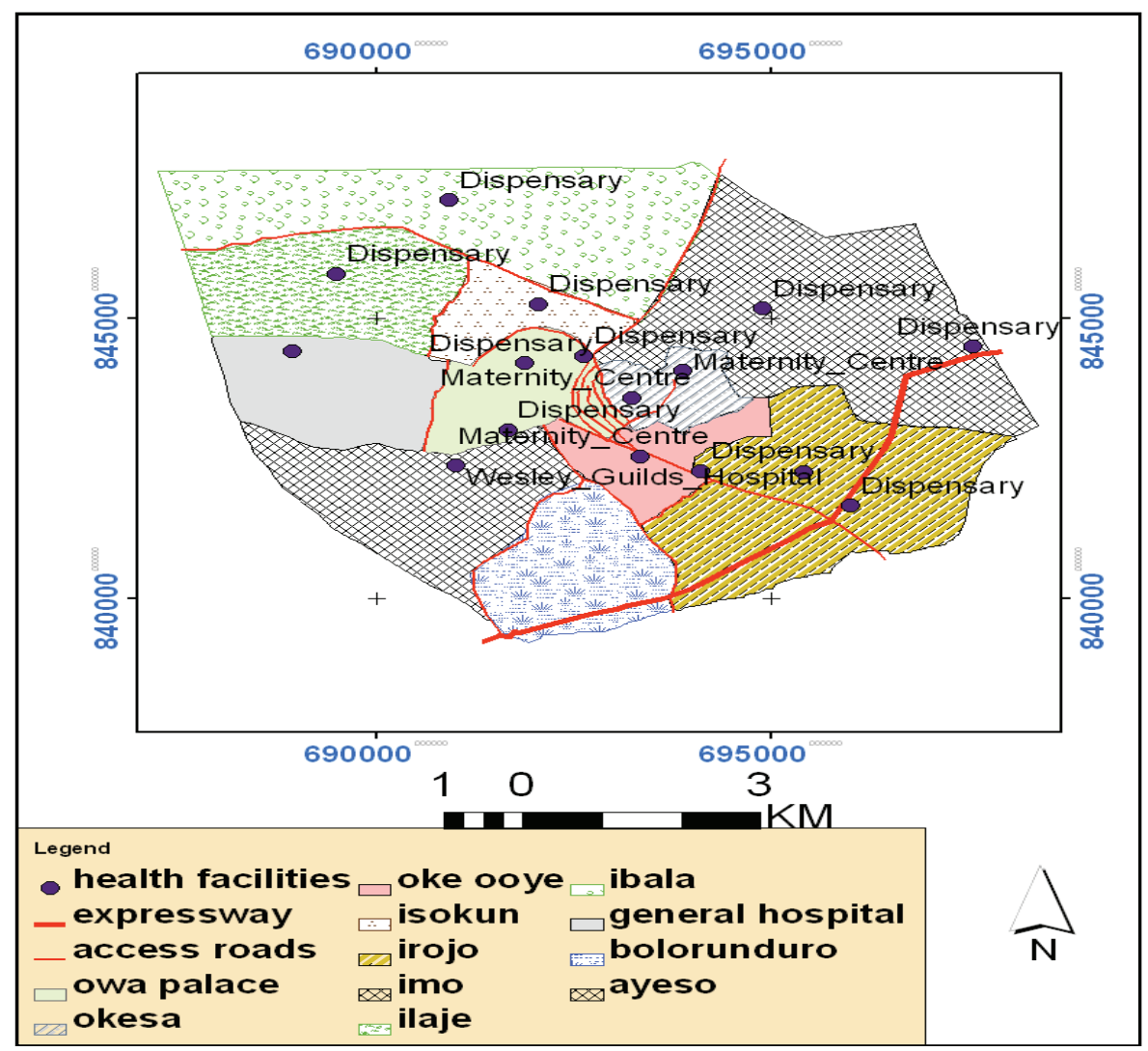

Figure 2: Pattern of the Distribution of Health Facilities in the Study area 
The Wesley Guild Hospital is located at Ayeso Zone while the State Hospital is located along Muroko road in the General Hospital Area zone. Nearly every zone in llesa has one particular type of health facility or another. Investigation on the personnel manning the health institutions revealed that all the public health centres are served by one medical Doctor Resident at the local Government Head Quarters of llesa East and West. Many of this category of public health centres are manned by Nurses and Ward Attendants. Many of them also lack necessary drugs in stock. Lack of drugs therefore are one of the factors respondents said usually force them to travel out to either the state hospital or Wesley Guild for medical treatment.

Table 1: Spatial Distribution of Health Services in llesa Township

\begin{tabular}{|l|c|c|c|c|c|}
\hline \multirow{2}{*}{ district } & \multicolumn{5}{|c|}{ TYPE of Health FACILITIES } \\
\cline { 2 - 6 } & $\begin{array}{c}\text { Government } \\
\text { hospital }\end{array}$ & $\begin{array}{c}\text { private } \\
\text { hospital/ } \\
\text { clinics }\end{array}$ & $\begin{array}{c}\text { Health } \\
\text { centres }\end{array}$ & dispensary & Total \\
\hline Owa's Palace & - & 1 & 5 & 1 & 7 \\
\hline Ilaje & - & 1 & 1 & - & 2 \\
\hline Imo & - & - & 2 & - & 2 \\
\hline Okesa & - & - & 2 & 1 & 3 \\
\hline Irojo & - & 1 & 2 & 1 & 4 \\
\hline Bolorunduro & - & 6 & 1 & - & 7 \\
\hline Ayeso & 1 & 2 & 1 & - & 4 \\
\hline General Hospital & 1 & 3 & 1 & - & 4 \\
\hline George Burton & - & - & 2 & 1 & 3 \\
\hline Oke-Ooye & - & 1 & 2 & - & 3 \\
\hline Isokun & - & 1 & 3 & - & 4 \\
\hline Total & 2 & 16 & 22 & 4 & 43 \\
\hline
\end{tabular}

The interaction matrix for the journey to health centres in llesa is shown in Table 2. The table indicates that $54.4 \%$ of the sampled population moved to Ayeso zone where the Wesley Guild Hospital is located in order to procure hospital services. Another $18.3 \%$ of the respondents moved to the General Hospital zone for the same purpose. The reason for these movements across the study area is because both the Wesley Guild Hospital and the State Hospital provide special services for women and children who form the bulk of respondent who leave their home for health centres every day. These two important heath institutions are centrally placed thus easily accessible to the populace. Consequently, there is overutilization of services provided by them. This is manifested by the long queues of patients especially at the Out Patient Department (OPD) units of both hospitals. The majority of the sampled respondents patronizing the two important hospitals expressed their dissatisfaction about the time wasted and energy spent in waiting for medical doctors to attend to their medical complaints.

Further analysis of table 5.2 revealed that $16.8 \%$ of the respondents who live in Irojo zone attend health care providers within their zone. An overwhelming proportion of the sampled population $76.2 \%$ move to Ayeso zone for the treatment of their illness. Only $1 \%$ of each of the respondents commutes to General and George Burton zones for the same purpose. Similarly at Okesa zone. $14.1 \%$ of the respondents attend the health centre in their zone, while $77.5 \%$ move to Ayeso zone for the same purpose. Only $2.8 \%$ of the respondents in Okesa commute to llaje, Imo and General Hospital zones for medical treatment. At Owa's palace, Imo, Okesa, Irojo, Boluwaduro, Ayeso, Isokun some respondents move to Ayeso zone for the treatment of their illness. 
Table 2: Matrix Showing the Patterns of Interaction of Journey to Health Service in llesa (in \%)

\begin{tabular}{|l|c|c|c|c|c|c|c|c|c|c|c|c||}
\hline $\begin{array}{l}\text { Name of } \\
\text { district }\end{array}$ & $\begin{array}{c}\text { Owa's } \\
\text { palace }\end{array}$ & Ilaje & Imo & Okesa & Irojo & $\begin{array}{c}\text { Bolorun } \\
\text { duro }\end{array}$ & Ayeso & $\begin{array}{c}\text { General } \\
\text { Hospital }\end{array}$ & $\begin{array}{c}\text { George } \\
\text { Burton }\end{array}$ & $\begin{array}{c}\text { Oke- } \\
\text { Ooye }\end{array}$ & Isokun & $\begin{array}{c}\% \\
\text { Total }\end{array}$ \\
\hline Owa's Palace & 28.4 & - & - & - & - & - & 56.8 & 12.5 & - & - & 2.3 & 100 \\
\hline Ilaje & 1.0 & 16.0 & 1.0 & - & - & - & 24.0 & 58.0 & - & - & - & 100 \\
\hline Imo & 0.9 & 0.9 & 41.1 & - & - & 2.8 & 51.4 & 2.8 & - & - & - & 100 \\
\hline Okesa & - & 2.8 & 2.8 & 14.1 & - & - & 77.5 & 2.8 & - & - & - & 100 \\
\hline Irojo & - & - & - & - & 16.8 & 14.9 & 76.2 & 1.0 & 1.0 & - & - & 100 \\
\hline Bolorunduro & - & 1.0 & 7.2 & - & 2.1 & 34.0 & 53.6 & 2.1 & - & - & - & 100 \\
\hline Ayeso & 1.3 & - & - & 0.6 & - & 1.3 & 76.9 & 20.0 & - & - & - & 100 \\
\hline $\begin{array}{l}\text { General } \\
\text { Hospital }\end{array}$ & - & 11.2 & - & 2.2 & 2.2 & - & 30.3 & 52.8 & - & - & 1.1 & 100 \\
\hline $\begin{array}{l}\text { George } \\
\text { Burton }\end{array}$ & 1.1 & 1.1 & 2.3 & 2.3 & 2.3 & 1.1 & 28.4 & 20.5 & 36.4 & 1.1 & 3.4 & 100 \\
\hline Oke-Ooye & 1.5 & 1.5 & - & - & 4.4 & - & 63.2 & 5.9 & - & 23.5 & - & 100 \\
\hline Isokun & 3.3 & 18.7 & 1.1 & - & 2.2 & - & 42.9 & 19.8 & 1.1 & 3.3 & 7.7 & 100 \\
\hline Total & 34 & 49 & 57 & 15 & 28 & 44 & 57.3 & 19 & 33 & 20 & 11 & 100 \\
\hline$\%$ & 3.2 & 4.6 & 5.4 & 1.4 & 2.6 & 4.2 & 54.1 & 18.3 & 3.1 & 1.9 & 1.0 & \\
\hline
\end{tabular}

\subsection{Distance to Health Care Providers}

The proximity to health care providers in urban centres in Nigeria to a large extent determines the degree of patronage by people who need medical help. The average distance travelled by respondents in llesa to Community Health Centres or Dispensaries is shorter than that travelled by patients to private medical centres. Figure 3 indicates that $44.3 \%$ of respondents who visit community health care providers travel less than $1 \mathrm{~km}, 12.4 \%$ and $23.7 \%$ of respondents cover between $1-2 \mathrm{~km}$ and $2-3 \mathrm{kms}$ for the same purposes. Less than $20 \%$ of the patients travel more than $3 \mathrm{kms}$ to the community health centres. Another $43.9 \%$ of the respondents travel less $1 \mathrm{~km}$ to private clinics. $15.2 \%$ and $8.2 \%$ travel between $1-2 \mathrm{~ms}$ and $2-3 \mathrm{kms}$ respectively for the same purpose.

In contrast, $32.9 \%$ of the patients who attend Government hospitals cover less than $1 \mathrm{~km}$ on their transit. Another $9.3 \%$ and $18.2 \%$ of respondents commute between $1-2 \mathrm{kms}$ and $2-3 \mathrm{kms}$ for the same purposes. More than $39 \%$ of the respondents who attend two major governments hospital in llesa spent more than $3 \mathrm{kms}$ on their journey in order to procure treatment for their illness. This shows clearly that the commuting distances to the hospitals in the city is higher than primary health care centres or dispensaries 


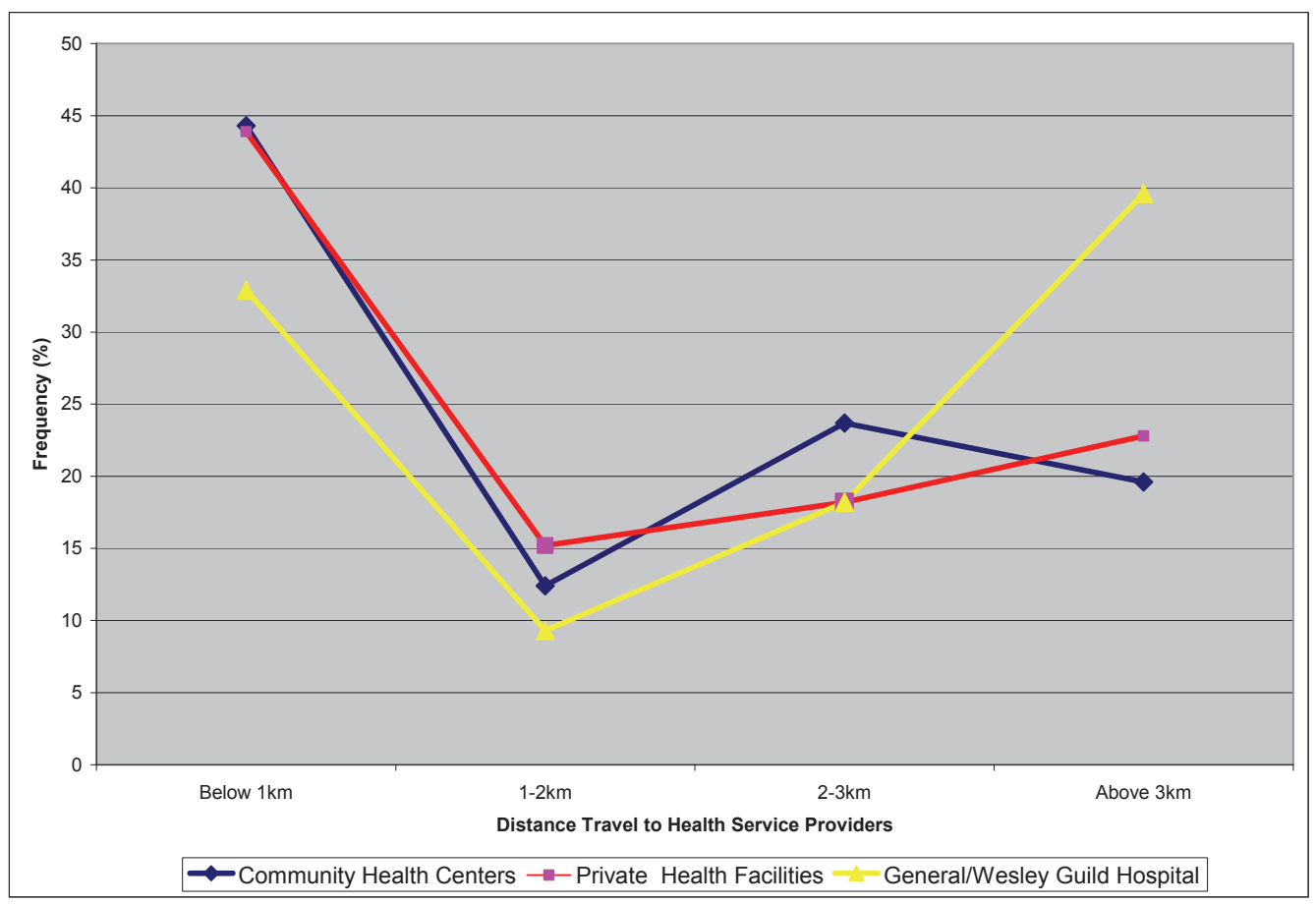

Figure 3 : Distance Travel to Health Facilities

\section{2 Mode of Transport to Health Providers}

The modal choice of respondents to the health providers is an important transport component of visits to health centres in llesa. Figure. 4 shows that $39.2 \%$ of the patients who attend community health centres commute on foot while $14.4 \%$, $18.6 \%$ and $26.8 \%$ rely on motorcycles, car and taxis respectively.

Further analysis reveals that $37.9 \%$ of the respondents commute on foot to a privately owned clinics. Another $15.2 \%$ and $28.8 \%$ of the patients depend on motorcycles and taxis to private clinics respectively. Only $3 \%$ of the patients rely on buses whose owners use as personal means of transport as opposed to commercial purpose.

However, Figure 4 indicates that $28.4 \%$ of respondents move to the General or Wesley Guild Hospitals on foot while $10 \%, 17.8 \%$ and $36.9 \%$ rely on motorcycles, car and taxis respectively to the same centres. It can be inferred from the above analysis that more than $54 \%$ of the respondents who attend General and Wesley Guild hospital rely mostly on automobile vehicles either personal or publicly provided. 


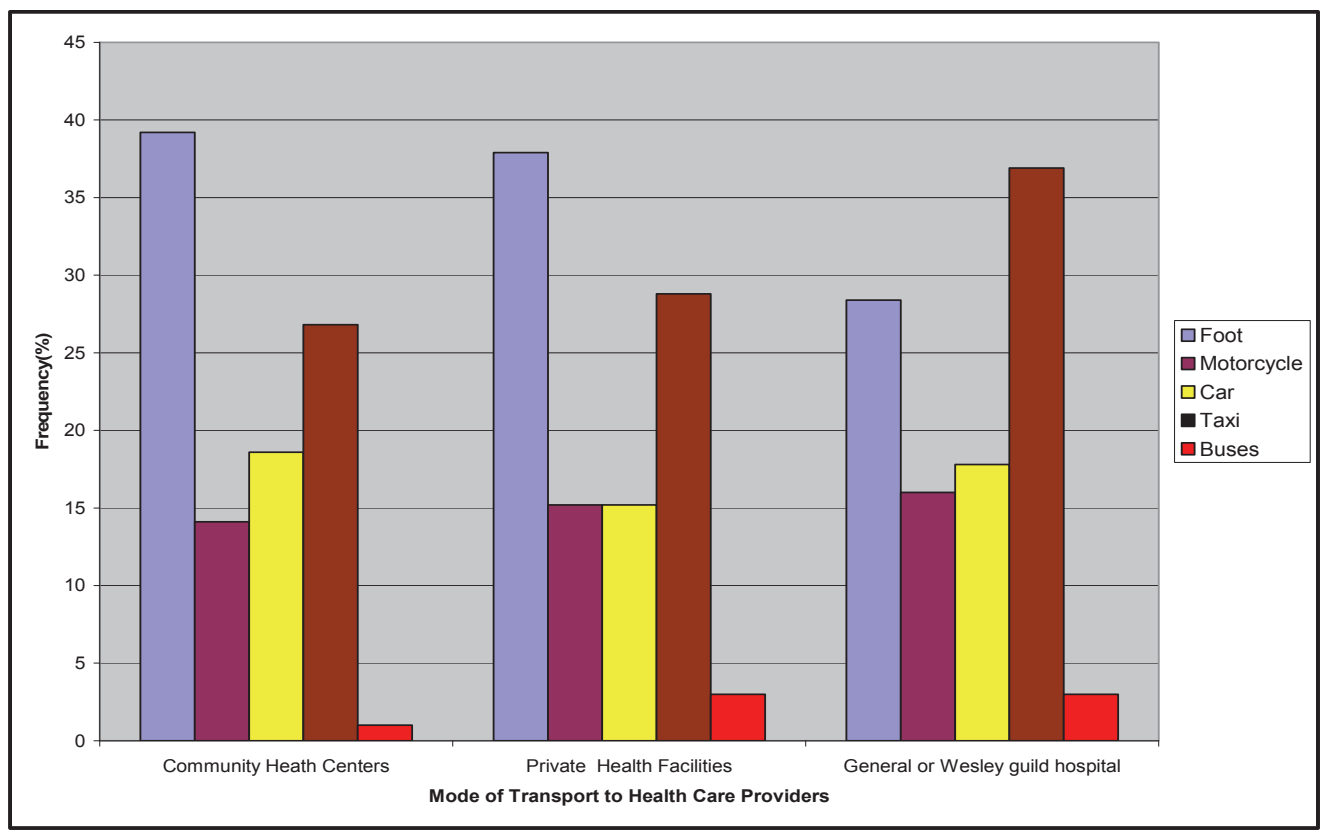

Figure 4: Percentage Distribution of Modal Choice to Health Care Provider

\subsection{Average Time Taken}

The average time taken to health facility in the study area is shown in table 3 below. The table indicates that $66 \%$ of the respondents who attend community health centre indicated that they spent less than 15 minutes to reach dispensaries or primary health centres. The remaining $34 \%$ spent between 15 and 30minutes. The proximity of these services to the population enables them spend less time to the nearest health centres in zones. For the entire study area, no commuter spends more than 30 minutes to primary Health Centres. Although more than $6 \%$ of the patients who attend government hospitals in llesa indicated that they spend more than 30minutes on their journey to consult medical doctors..

Table 3: Percentage Distribution of the Average Time Taken to Health Care Providers in llesa

\begin{tabular}{|l|c|c|c|c|c|}
\hline \multirow{2}{*}{$\begin{array}{l}\text { HEALTH CARE } \\
\text { PROVIDERS }\end{array}$} & \multicolumn{5}{|c|}{ TIME } \\
\cline { 2 - 6 } & $\begin{array}{c}\text { Below 15 } \\
\text { Minutes }\end{array}$ & $\begin{array}{c}15-30 \\
\text { Minutes }\end{array}$ & $\begin{array}{c}30-45 \\
\text { Minutes }\end{array}$ & $\begin{array}{c}45-60 \\
\text { Minutes }\end{array}$ & $\begin{array}{c}\text { Above 60 } \\
\text { Minutes }\end{array}$ \\
\hline Community Health Care & 66 & 34 & - & - & - \\
\hline Private Hospitals & 72.2 & 27.8 & - & - & - \\
\hline Government Hospital & 70.1 & 22.8 & 5.4 & 1.3 & 0.4 \\
\hline Zonal average & 69.8 & 26.1 & 3.1 & 0.7 & 1.6 \\
\hline
\end{tabular}

\subsection{Transport Cost to Health Care Providers}

The physical location of health services relative to some other factors such as location of residence, transport cost, condition of roads and many other logistic difficulties are linked with utilization of medical services (Chandra and Eric, 2000). An analysis of figure 5 indicates that $25.9 \%$ of the respondents who commute on foot spend nothing on fare to health care providers. They also live close to the health facilities in each zone. 
Further analysis of the table also indicates that $27.2 \%, 25.8 \%$ and $8.8 \%$ of the respondents spend between N20$\mathrm{N} 30, \mathrm{~N} 30-\mathrm{N} 40$ and N40-N50 as transport fare to various health care providers. A sizeable number of the respondents $(12.3 \%)$ spend more than N50 on transport fares for the same purpose. The respondents in this category live in Imo, George Burton, and Oke-Ooye zones where poor road networks constitutes a major constraints to mobility and easy access to other zones

The few motorcyclists that ply the urban poor roads therefore charge exorbitant transport fares which add to the burden of the urban poor. Thus high transport fares to health services can limit the access of the poor to such facilities. Most of the respondents in this category would rather trek in order to procure heath services.

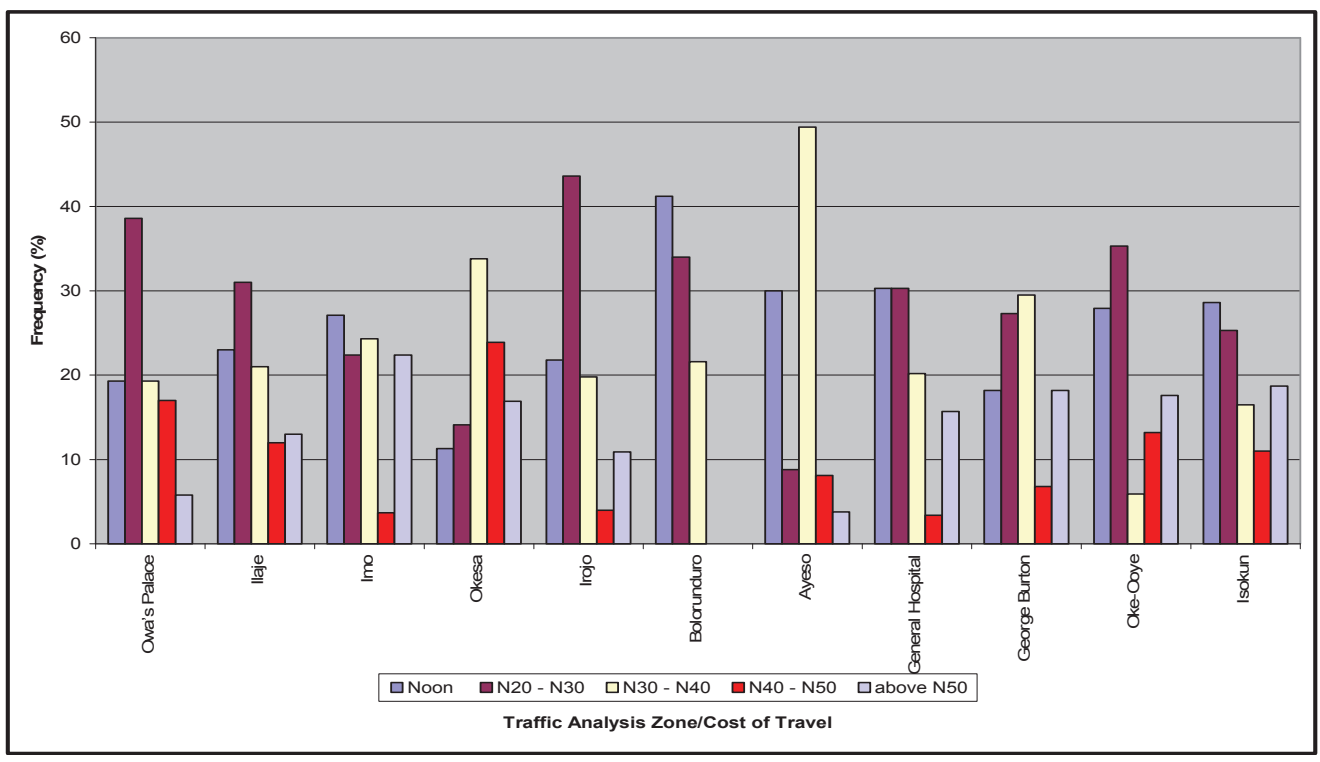

Figure 5: Transport Cost to Health Care Providers

\subsection{Frequency Of Trip to Health Care Providers in The Study Area}

The frequency of trips to the health services in llesa even though interesting must be interpreted with caution. It may be hypothetical that since low income earners get sick more easily than the high income earners, it is expected that the former would visit health care providers more frequently. ( Adesanya el tal, 2002). But contrary to this hypothesis table 4 reveals that $95.5 \%$ of respondents with low income made only one trip to health services in the last six months for one reason or the other. The remaining $4.5 \%$ of the low income earners visited health care providers twice within the same period.

In contrast, $21.4 \%$ of high income earners visited health care providers only once within the last six months while $25 \%$ and $53.6 \%$ visited the hospitals twice and thrice respectively within the same period. This pattern of movement may be interpreted to mean that the well to do respondents take their health more seriously than the poor, and would visit the hospital at any time they notice anything unusual at their body. As a matter of fact, some of the respondents on this category seem they have family doctor who naturally check on them from time to time. The observed pattern in llesa is similar to Adesanya et al (2002) study of mobility characteristics of urban poor in the six geo-political zones in Nigeria which revealed that low income earners make less frequent visit to hospital because of cost of transport and treatment charges 
Table 4: Frequency of Trip to Health Services in the Study Area.

\begin{tabular}{|l|c|c|c|c|c|c|}
\hline \multirow{2}{*}{ Income } & \multicolumn{2}{|c|}{ Once } & \multicolumn{2}{c|}{ Twice } & \multicolumn{2}{c|}{$\begin{array}{c}\text { more than two } \\
\text { times }\end{array}$} \\
\cline { 2 - 7 } & No & $\%$ & No & $\%$ & No & $\%$ \\
\hline $\begin{array}{l}\text { Less than N20,000 } \\
\text { LOW INCOME }\end{array}$ & 589 & 95.9 & 25 & 4.1 & - & - \\
\hline $\begin{array}{l}\text { N21,000 - N 40,000 } \\
\text { MEDIUM INCOME }\end{array}$ & 100 & 55.5 & 50 & 26.6 & 35 & 18.6 \\
\hline $\begin{array}{l}\text { N 41,000 above } \\
\text { HIGH INCOME EARNER }\end{array}$ & 6 & 21.4 & 7 & 25.0 & 15 & 53.6 \\
\hline
\end{tabular}

The result of the analysis of Variance reveals that there is a significant difference on the distance travelled, modal choice, transport cost and average time taken to commute to health care providers in difference zones of the study area. Table 5 reveals that the result of the analysis is significant at (Distance travelled $F=5.43, p<0.05$; Modal Choice $F=5.81$, $p<0.05$; Transport Cost $F=1.93, p<0.05$ : Travel Time, $F=8.38, p<0.05)$.

Table 5: Analysis of Variance of the Household's Travel Characteristics to Health Facility in the Study Area

\section{ANOVA}

\begin{tabular}{|ll|r|r|r|r|r|}
\hline & & \multicolumn{1}{|c|}{$\begin{array}{c}\text { Sum of } \\
\text { Squares }\end{array}$} & \multicolumn{1}{c|}{ df } & Mean Square & \multicolumn{1}{c|}{ F } & \multicolumn{1}{c|}{ Sig. } \\
\hline Distance from & Between Groups & 216.508 & 10 & 21.651 & 5.431 & .000 \\
Residence to Hospital & Within Groups & 2347.877 & 589 & 3.986 & & \\
& Total & 2564.385 & 599 & & & .000 \\
\hline Transport Mode to & Between Groups & 227.404 & 10 & 22.740 & 5.813 & \\
Hospital & Within Groups & 2304.089 & 589 & 3.912 & & \\
& Total & 2531.493 & 599 & & & .039 \\
\hline Transport Cost to & Between Groups & 78.549 & 10 & 7.855 & 1.929 & \\
Hospital & Within Groups & 2398.969 & 589 & 4.073 & & \\
& Total & 2477.518 & 599 & & & \\
& & 62.210 & 10 & 6.221 & 8.379 & .000 \\
\hline Travel Time to Hospital & Between Groups & 437.284 & 589 & .742 & & \\
& Within Groups & 499.493 & 599 & & & \\
& Total & & & & \\
\hline
\end{tabular}

\subsection{Determinants of Households Accessibility to Health facilities}

A multiple regression analysis was used to determine the important variables that influence the accessibility of urban residents to health care services in the study area, The frequency of trips to health care providers represent the dependent variable, while the location pattern of health facility, socio economic characteristics of the households such as income level, educational background and transport attributes such as modal choice, distance travelled and transport cost to health services represent the independent variables. The table 6 reveal that the location of health facilities and the average travel time are more significant at $p=0.000$. This shows that the accessibility of urban residents to health care providers is mostly affected by the distribution patterns of health care services in the study area. Similarly the transport attributes such as modal choice and distance travelled to health care providers are significant at $p=0.002$ and $p=0.013$ respectively. While the socio economic characteristics of the urban residents such as income and educational background are significant at $p=0.014$ and $p=0.158$ respectively. 
Table 6a: Determinant of Households Accessibility to Health Facility in the Study Area

\section{Model Summary}

\begin{tabular}{|c|c|c|c|c|}
\hline Model & $\mathrm{R}$ & $\mathrm{R}$ Square & $\begin{array}{c}\text { Adjusted R } \\
\text { Square }\end{array}$ & $\begin{array}{c}\text { Std. Error of the } \\
\text { Estimate }\end{array}$ \\
\hline 1 & $.849(\mathrm{a})$ & .721 & .717 & .548 \\
\hline
\end{tabular}

a. Predictors: (Constant), Travel Time to Hospital, Monthly Income Range, Educational Background, Transport Cost to Hospital, Distric Code: Health, Distance from Residence to Hospital, Transport Mode to Hospital

\section{ANOVA(b)}

\begin{tabular}{|cc|c|c|c|c|c|}
\hline Model & & $\begin{array}{c}\text { Sum of } \\
\text { Squares }\end{array}$ & Df & Mean Square & F & Sig. \\
\hline \multirow{3}{*}{1} & Regression & 457.718 & 7 & 65.388 & 218.115 & $.000(\mathrm{a})$ \\
& Residual & 177.475 & 592 & .300 & & \\
& Total & 635.193 & 599 & & & \\
\hline
\end{tabular}

a. Predictors: (Constant), Travel Time to Hospital, Monthly Income Range, Educational Background, Transport Cost to Hospital, Distric Code: Health, Distance from Residence to Hospital, Transport Mode to Hospital

b. Dependent Variable: Trip Frequency to Hospital

\section{Coefficients(a)}

\begin{tabular}{|ll|c|c|c|c|c|c|}
\hline Model & \multicolumn{2}{|c|}{$\begin{array}{c}\text { Unstandardized } \\
\text { Coefficients }\end{array}$} & $\begin{array}{c}\text { Standardized } \\
\text { Coefficients }\end{array}$ & $\mathrm{T}$ & Sig. \\
\hline & & $\mathrm{B}$ & Std. Error & Beta & $\mathrm{B}$ & Std. Error \\
\hline (Constant) & .247 & .061 & & 4.049 & .000 \\
& Educational Background & .025 & .017 & .034 & 1.415 & .158 \\
Monthly Income Range & -.065 & .022 & -.068 & -2.928 & .004 \\
Distric Code: Health & .142 & .009 & .502 & 15.625 & .000 \\
Distance from Residence to Hospital & .062 & .025 & .124 & 2.490 & .013 \\
Transport Mode to Hospital & .076 & .025 & .152 & 3.058 & .002 \\
Transport Cost to Hospital & .021 & .020 & .042 & 1.073 & .283 \\
Travel Time to Hospital & .150 & .038 & .133 & 3.990 & .000 \\
\hline
\end{tabular}

a Dependent Variable: Trip Frequency to Hospital

\section{Conclusion and Recommendations}

This paper has examined the accessibility characteristics of urban residents to health facility in llesa in Southwestern part of Nigeria. The analysis reveals that people have less access to health facility in the study area. Many of the urban residents commute long distances and spend a large proportion of their income to procure health services. The paper then concludes by advocating for the upgrading of some of the public health facilities to the status of General hospital. Private health service providers should be encouraged by the government to establish new ones in some disadvantaged zones. Further studies are needed however to examine the human resources and material needs of the existing health facilities in the study area, for effective planning and provision of qualitative health services to the urban population In llesa and cities of similar sizes in Nigeria. 


\section{References}

Adagbasa, E (2008) Measuring Physical Accessobility to Public Health Centres Using GIS. An Unpublished M,Sc. Thesis ,Depaetment of Geography,University of Ibadan, Ibadan,

Adetuni, M.A. (2010): Spatial Analysis of Urban Mobility Pattern in llesa, Osun State.Unpublished Ph. D Thesis Department of Geography, Obafemi Awolowo University, lle-lfe, Nigeria

Adesanya, A.; Adeniji, K and Daramola A.Y. (2002): Transport Perspective of poverty in Nigeria a Multi- dimensional perspective. Edited by Ajakaiye, D..O. and. Olomola, A.S Pp. 235-283

Andrew,J. S (1997) Access to Health Care and Minorities. Checkout Reclamationgallery.com, http://academic.udayton.edu /health/03access/97schwel.htm.

Berry, B. J. L (1968) Geography of Market Centres and Retail Distribution. Englewood Cliffs,New Jersey: Prentice-Hall

Chandra, A. and Eric, T. (2000) Does Public Infrastructure Affect Economic Activity? Evidence from Rural Interstate Highway System" Regional Science and Urban Economics, Vol. 30 PP 457-490.

CIET Canada (2000): Service Delivery Survey: Second Cycle 2000 Preliminary Findings. CIET Canada,Dhaka

Christaller, W. (1933) Central Place Theory in Southern Germany. Englewood Cliffs, New Jersey: Prentice-Hall

Ensor, J. and Copper S. (2004): Overcoming Barrier to Health Services access: Influencing the Demand Side. Health Policy Plan 19(2): $69-79$.

July B; Rakhi, B.; Maureen C.; Somik, L. and Akie, T. (2005): Urban Poverty and Transport. The Case of Mumbai, World Bank Policy Research Working Paper 3693,

NPC (2006): National Population Census of the Federal Republic of Nigeria Abuja National Population Commission.

Olawuni, P.O. (2007): Households Environmental Factors and Residents Health in Osogbo, Nigeria. Unpublished Ph.D Thesis Department of Urban and Regional Planning, Obafemi Awolowo University, lle-lfe

Peel, J.D.Y (1983): ljesas and Nigerians. The incorporation of a Yoruba Kingdom,1890s - 1970s. Cambridge University Press (1983) Cambridge - London September 1985, Pp. 1-75.

Sauerborn, R.; Bodart C. and Essomba, R.O. (1995): Recovery of Recurrent Health Service Costs through Provincial Health Funds in Cameroon. Soc. Sci Med 40(12): 1731 - 1739.

Terra de Souza, A.C; Peterson, K.E.; Andrade, F.M.O; Gardner, J. and Ascherio, A. (2000): Circumstances of Post-neonatal Deaths in Ceara, Northeast Brazil: Mothers' health Care-seeking Behaviours during their Infants fatal illness. Social Sciences Med. 51: 1675 - 93. 